\title{
Profile of intractable epilepsy in a tertiary referral center in upper
}

\section{Assam}

\author{
Sarmah B. ${ }^{1 *}$, Rajkhowa K. ${ }^{2}$ \\ DOI: https://doi.org/10.17511/ijmrr.2019.i03.11 \\ 1* Binod Sarmah, Associate Professor, Department of Neurology, Assam Medical College and Hospital, Dibrugarh, Assam, India. \\ 2 Kamal Rajkhowa, Resident Physician, Department of Neurology, Assam Medical College and Hospital, Dibrugarh, Assam, India.
}

Introduction: Epilepsy is a common and diverse disorder with many different causes.Outcomes are varied with $60-70 \%$ of newly diagnosed people rapidly entering remission after starting treatment, and $20-30 \%$ developing a drug-resistant epilepsy with consequent clinical and psychosocial distress. Methods: It is a Descriptive Cross-sectional study which was conducted in Assam Medical College and Hospital, Dibrugarh from April 2014 to April 2016. A total of 42 patients of IE attending the neurology, paediatrics and medicine department were included in the study. Results: Forty-two patients (males 24, females 18) with intractable epilepsy were included for the study. Maximum patients were in between $20-40$ years of age $(42.9 \%)$ and their mean duration of epilepsy was 13.2 \pm 7.13 years. The seizure frequency varied from once every month to more than 200 per (mean $26.2 \pm 24.17)$ month. Twenty-six patients $(61.9 \%)$ had partial seizures, $8(19.1 \%)$ patients had generalized seizures and $8(19.1 \%)$ had multiple seizure semiology. Thirty-six patients had risk factors of intractable epilepsy. Seven $(16.6 \%)$ patients were having family history of epilepsy and $4(9.5 \%)$ patients had history of febrile seizures. Mesial temporal lobe sclerosis (MTLS) and birth hypoxia are the two major risk factors for intractable epilepsy. EEG was abnormal in $66.7 \%$ cases, with generalized background slowing in $19.1 \%$, focal slowing in $14.2 \%$, generalized epileptiform discharges in $9.5 \%$ and focal epileptiform discharges in $23.8 \%$. CT brain was abnormal in $18(42.9 \%)$ patients. MRI brains were abnormal in 25 out-off 36 patients (69.4\%). Carbamazepine was the most commonly used drug (57.1\%) followed by clobazam (47.6\%). Phenytoin, levetiracetum, Phenobarbitone, oxcarbazepine, zonisemide, lacosemide are the other AEDs used in combination. Conclusion: This study showed, patients with partial seizures, birth hypoxia, history of febrile seizures, family history of seizures, structural brain abnormalities and background EEG abnormalities were the most common risk factors for development of intractable epilepsy.

Keywords: Epilepsy, Intractable epilepsy, Seizures, MTLS, Birth hypoxia

\section{Corresponding Author}

Binod Sarmah, Associate Professor, Department of Neurology, Assam Medical College and Hospital, Dibrugarh, Assam, India.

Email: b_sarmah2007@yahoo.com

\section{How to Cite this Article}

Sarmah B, Rajkhowa K. Profile of intractable epilepsy in a tertiary referral center in upper Assam. Int J Med Res Rev. 2019;7(3):212-217.

Available From

https://ijmrr.medresearch.in/index.php/ijmrr/article/ view/1061
To Browse

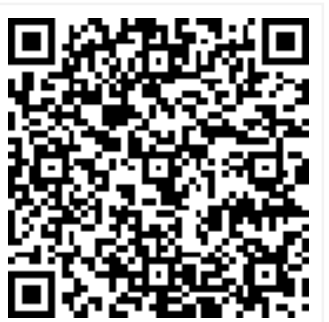

Manuscript Received 2019-04-14

Conflict of Interest No

(C) 2019 by Binod Sarmah, Kamal Rajkhowa and Published by Siddharth Health Research and Social Welfare Society. This is an Open Access article licensed under a Creative Commons Attribution 4.0 International License https://creativecommons.org/licenses/by/4.0/ unported [CC BY 4.0].

Review Round 2 2019-04-30

Riew Round 2019-04-24

unding

Ethical Approval

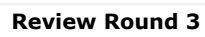

Review Round 3

Accepted 2019-05-06 Yes
Note 


\section{Introduction}

Epilepsy is a common and diverse disorder with many different causes. Outcomes are varied with 60 $-70 \%$ of newly diagnosed people rapidly entering remission after starting treatment, and 20-30\% developing a drug-resistant epilepsy with consequent clinical and psychosocial distress [1]. About one third of patients with a first unprovoked seizure will have further seizures within five years, and about three quarters of those with two or three unprovoked seizures have further seizures within four ears [2]. There are a number of factors which are predictors of poor seizures control and leading to medically refractory epilepsy $[3,4]$.

These include organic brain lesions, partial seizures, multiple seizure types, high seizure frequency and abnormal background EEG activity. Till date, studies on intractable epilepsy (IE) are limited in India. The present study has been undertaken in Assam Medical College and Hospital, Dibrugarh, Assam to find out the profile of intractable epilepsy in Upper Assam.

\section{Material and Methods}

It is a Descriptive Cross-sectional study which was conducted in Assam Medical College and Hospital, Dibrugarh from April 2014 to April 2016. A total of 42 patients of IE attending the neurology, paediatrics and medicine department were included in the study. While selecting the study subjects, only those patients who had uncontrolled seizures despite two appropriate first line drugs for two years, were included. All included cases were underwent detail history of seizure semiology, duration of seizures, perinatal brain injury in the form of birth hypoxia, forceps delivery, history suggestive of CNS infections, history of head trauma, family history of seizure were recorded in proforma.

Details regarding antiepileptic drugs (AED) were recorded i.e. number of drugs, duration of therapy, dosage, and compliance. Seizures were classified according to International League Against Epilepsy Classification.All patients were examined in detail with special emphasis on presence or absence of any neurocutaneous markers, subcutaneous nodules, behavioural disorders, mental retardation and neurological deficits. All the patients were subjected to EEG and CT examination. MRI examinations were done in 36 patients.

\section{Results}

A total of 42 patients (males 24, females 18) of IE were registered over 2 year period. The age of the patients ranged from 8-66 (mean 32.6) years. Maximum patients $(42.9 \%)$ were in the age group of 20-40 years. The duration of epilepsy varied from 4-52 years (mean+SD = 13.2 7.13 years). The seizure frequency varied from once every month to more than 200 per (mean+SD = 26.2 \pm 24.17) month.Fourteen patients $(33.3 \%)$ had seizure frequency more than one seizure per day, $23.8 \%$ had more than one seizure per week and only $23.8 \%$ had seizure frequency more than one seizure per month. Twenty-six patients $(61.9 \%)$ had partial seizures, $8(19.1 \%)$ patients had generalised seizures and $8(19.1 \%)$ had multiple seizure semiology. Amongst patients with partial seizures, $2(4.7 \%)$ had simple partial seizures and $8(19.1 \%)$ had complex partial seizures and 16 (38.0\%) had partial seizures with secondary generalization (Table 1).

Table-1: Baseline characteristics of the study population $(n=42)$.

\begin{tabular}{|c|c|}
\hline Men & $24(57.1 \%)$ \\
\hline Women & $18(42.9 \%)$ \\
\hline \multicolumn{2}{|l|}{ Age of patients in years } \\
\hline $0-20$ yrs & $10(23.8 \%)$ \\
\hline $20-40 y r s$ & $18(42.9 \%)$ \\
\hline $40-60 y r s$ & $10(23.8 \%)$ \\
\hline$>60 y r s$ & $4(9.5 \%)$ \\
\hline Mean & $32.6 \pm 27.3$ \\
\hline \multicolumn{2}{|l|}{ Duration of epilepsy in yrs } \\
\hline$<5 y r s$ & $6(14.2 \%)$ \\
\hline 5 -10yrs & $8(19.1 \%)$ \\
\hline $10-20$ yrs & $12(28.6 \%)$ \\
\hline $20-30 y r s$ & $10(23.8 \%)$ \\
\hline$>30 y r s$ & $6(14.2 \%)$ \\
\hline Mean duration of epilepsy & $13.2 \pm 7.13 \mathrm{yr}$ \\
\hline \multicolumn{2}{|l|}{ Seizure Frequency at inclusion } \\
\hline$>1$ seizure per day & $14(33.3 \%)$ \\
\hline$>1$ seizure per week & $16(38.0 \%)$ \\
\hline$>1$ seizure per month & $10(23.8 \%)$ \\
\hline Mean seizure frequency per month & $26.2 \pm 24.17$ \\
\hline Family history of seizure & $7(16.6 \%)$ \\
\hline Febrile seizure in childhood & $4(9.5 \%)$ \\
\hline \multicolumn{2}{|l|}{ Seizure types } \\
\hline Primary generalized seizure: GTCS & $8(19.1 \%)$ \\
\hline Partial seizure & $26(61.9 \%)$ \\
\hline Simple partial & $2(4.7 \%)$ \\
\hline Complex partial & $8(19.1 \%)$ \\
\hline
\end{tabular}




\begin{tabular}{|l|l|}
\hline Partial with secondary generalisation & $16(38.0 \%)$ \\
\hline Multiple seizure semiology & $8(19.1 \%)$ \\
\hline
\end{tabular}

Table-2: Risk factors of intractable epilepsy in study population.

\begin{tabular}{|l|l|}
\hline \multicolumn{1}{|c|}{ MTLS } & \multicolumn{1}{c|}{$1 \mathbf{1 1}(\mathbf{2 6 . 1} \%)$} \\
\hline Birth hypoxia & $9(21.4 \%)$ \\
\hline CNS infections & $6(14.2 \%)$ \\
\hline Head trauma & $4(9.5 \%)$ \\
\hline Vascular malformation & $2(4.7 \%)$ \\
\hline Tuberous sclerosis & $1(2.3 \%)$ \\
\hline Focal cortical dysplasia & $1(2.3 \%)$ \\
\hline Arachnoid cyst & $1(2.3 \%)$ \\
\hline stroke & $2(4.7 \%)$ \\
\hline Unknown & $5(11.9 \%)$ \\
\hline
\end{tabular}

We found various risk factors of intractable epilepsy in 36 patients. Family histories of epilepsies were found in $7(16.6 \%)$ patients and histories of febrile seizures were found in $4(9.5 \%)$ patients.

Table-3: EEG, CT and MRI abnormalities in study population.

\begin{tabular}{|l|l|}
\hline \multicolumn{2}{|l|}{$n$} \\
\hline EEG(n=42 & $8(19.1 \%)$ \\
\hline Generalized background slowing & $6(14.2 \%)$ \\
\hline Focal slowing & $4(9.5 \%)$ \\
\hline Generalized epileptiform discharges & $10(23.8 \%)$ \\
\hline Focal epileptiform discharges & $14(33.3 \%)$ \\
\hline Normal & \\
\hline CT and MRI findings & $18(42.9 \%)$ \\
\hline Abnormal CT ( $n=42)$ & $25(69.4 \%)$ \\
\hline Abnormal MRI(n=36) & $11(26.6 \%)$ \\
\hline MTLS & $9(21.4 \%)$ \\
\hline Periventricular ischaemic lesions & $6(16.7 \%)$ \\
\hline Gliotic lesions & $4(9.5 \%)$ \\
\hline NCC/calcified granuloma & $1(2.3 \%)$ \\
\hline Sub-ependymal calcification & $1(2.3 \%)$ \\
\hline Focal cortical dysplasia & $2(4.7 \%)$ \\
\hline AVM & $1(2.3 \%)$ \\
\hline Arachnoid cyst &
\end{tabular}

EEG was done in all cases and abnormality in EEG was found in $28(66.7 \%)$ patients. CT brain was done in all 42 patients and abnormalities were detected in $18(42.9 \%)$ patients. MRI brain was done in 36 patients and abnormalities were detected in 25(69.4\%) patients.

All patients who had normal brain CT were undergone MRI study and additional brain abnormalities were detected in these include medial temporal sclerosis (MTLS), arachnoid cyst, focal cortical dysplasia (FCD), gliotic lesions.
Table2 showing various EEG, CT and MRI abnormalities in the study.

Table-4: Antiepileptic drug profiles.

\begin{tabular}{|l|l|}
\hline \multicolumn{1}{|c|}{ Two AEDs } & \multicolumn{1}{c|}{$\mathbf{6 ( 1 4 . 2 \% )}$} \\
\hline Three AEDs & $22(52.4 \%)$ \\
\hline Four AEDs & $14(33.3 \%)$ \\
\hline Carbamazepine & $24(57.1 \%)$ \\
\hline Phenytoin & $12(28.6 \%)$ \\
\hline Sod.Valproate & $8(19.1 \%)$ \\
\hline Phenobarbitone & $4(9.5 \%)$ \\
\hline Levetiracetum & $18(42.9 \%)$ \\
\hline Lacosemide & $6(14.2 \%)$ \\
\hline Zonisemide & $4(9.5 \%)$ \\
\hline Oxcarbazepine & $7(16.7 \%)$ \\
\hline Lamotrigine & $2(4.7 \%$ \\
\hline Clobazam & $20(47.6 \%)$ \\
\hline
\end{tabular}

Among the 42 patents, 6(14.2\%) patients were receiving a combination of 2 antiepileptic drugs (AED), 22(52.4\%) patients were receiving combination of3 AEDs and remaining 14(33.3\%) patients were receiving combination of 4 or more AEDs. Carbamazepine was the most commonly used drug $(57.1 \%)$ followed by clobazam (47.6\%). Phenytoin, levetiracetum, Phenobarbitone, oxcarbazepine, zonisemide, lacosemide are the other AEDs received by the patients (Table 4 ).

\section{Discussion}

Epilepsy is one of the most common serious neurological conditions, accounting for $1 \%$ of the global burden of disease, based on disabilityadjusted life years, the number of person years lost due to disability and premature death [5]. Ten percent of the world's population will have at least one seizure during their lifetime and one-third of these will develop epilepsy at any given time [6].

In countries where adequate diagnosis and treatment are available, $15-35 \%$ of people with epilepsy have seizure that are uncontrolled by medication (IE)[7-9]. The magnitude of the problem of IE in India is unknown. Radhakrishnan et al estimated 20,000-40,000 patients with IE in India [10].

Intractability occurs with equal frequency in both sexes [11]. In our study, $57.1 \%$ cases were male and $42.9 \%$ were female which could be due to non reporting of female cases due to social stigma or other causes. In our study, partial seizures were the most common type of seizures accounting $61.9 \%$ cases. 
Mattson et al. observed poor seizure control in patients with partial seizures as compared to generalized seizure after one year of treatment [12]. However there are studies which found that generalized and myoclonic seizures have the worstoutcome and also some who did not find seizure type as a predictor of intractability [13-16]. Different risk factors and causes have been associated with intractable epilepsy. Gururaj et al. in their study population reported that developmental delay, neuro-logical deficits, high frequency of seizures at onset and an abnormal brain imaging were associated with intractability [17].

Berg et al. reported a history of status epilepticus, infantile spasms, neonatal seizures, microcephaly to be associated with IE [18]. Kwan and Brodie found patients having many seizures before treatment and inadequate response to initial treatment are likely to have refractory epilepsy [19]. Similarly Kwong et al. observed abnormal neurologic status and early break through attacks after treatment initiation were predictors of IE [20].

An earlier study done in the pediatric population in India by Singhvi et al. found neuroinfections to be a leading cause of intractable epilepsy [21]. In our study, 6(14.2\%) cases had CNS infections among which neurocysticercosis (NCC) was predominant. History of febrile seizure is one of the risk factor for IE. Camfield et al observed that prolonged febrile seizures were associated with intractable epilepsy [22]. In our study, 9.5\% cases had febrile seizure in childhood which is identical to the previous study.

In our study family history of epilepsy were found in $16.6 \%$ cases, signifies role of family history of epilepsy in IE. The seizure remission is less likely in symptomatic epilepsy, caused by either defined acquired brain damage or less well- defined perinatal causes, manifested by gross neuro-logical deficits or MR $[23,24]$. Our study shows that presence of a known epileptogenic structural lesion is the most important predictor of intractable epilepsy. MTLE by far the most common risk factor of IE in our series accounting $26.1 \%$ cases.

Other important epileptogenic structural lesions found on imaging studies were birth hypoxia, CNS infections, head trauma, neurocutaneous syndrome, vascular malformation, neuronal migration defects and post stroke gliosis. The incidence of cerebral palsy in epilepsy has been reported to be $8 \%$ [25]. In our study, we have found more numbers of cerebral palsy as a predictor of IE (21.4\%).
The outcome of seizure is poorer if EEG shows background abnormality and focal epileptiform activity [26]. In our study, EEG was abnormal in $66.7 \%$ cases, with generalized background slowing in $19.1 \%$, focal slowing in $14.2 \%$, generalized epileptiform discharges in $9.5 \%$ and focal epileptiform discharges in $23.8 \%$. In our study CT were abnormal in $42.9 \%$ and MRI were abnormal in $69.4 \%$ cases, signifying role of structural lesions in development IE.

Many studies have shown that addition of second drug in patients with IE controlled seizures only in additional $10-15 \%$ of cases with increased toxicity [27-29]. In our study we have noticed, in spite of combination of drugs used and withproper doses, $14.2 \%$ patients on 2 drugs, $52.4 \%$ on 3 drugs and $33.3 \%$ patients on 4 drugs had uncontrolled seizures.

\section{Conclusion}

Intractable epilepsy has diverse risk factors for the development of intractability. Our study showed, patients with partial seizures, birth hypoxia, history of febrile seizures, family history of seizures, structural brain abnormalities and background EEG abnormalities were the predictors of intractable epilepsy.

\section{What this study Adds to existing knowledge?}

This study demonstrated that there are different risk factors/predictors of development of intractable epilepsy. Most common risk factors are partial seizures, birth hypoxia, history of febrile seizures in childhood, structural brain lesions, family history of seizures and EEG background abnormalities.

\section{Reference}

01. Kim LG, Johnson $T L$, Marson $A G$, et al. Prediction of risk of seizure recurrence after a single seizure and early epilepsy- further results from the MESS trial. Lancet Neurol. 2006 Apr;5(4)317-22.

DOI: $10.1016 / \mathrm{S} 1474-4422(06) 70383-0$ [Crossref]

02. Hauser WA, Rich SS, Lee JR, et al. Risk of recurrent seizures after two unprovoked seiz ures. N Engl J Med. 1998 Feb 12;338(7)429-34. DOI: $10.1056 /$ NEJM 199802123380704 [Crossref] 
03. Shorvon SD, Sander JWAS. Temporal patterns of remission and relapse of seizures in patients with epilepsy, In-SchmidtD and Morelli PL (eds), Intractable epilepsy, Experimental and Clinical aspects. LERS Monograph Series, Raven Press, New York. 1986;5;13-24.

[Crossref]

04. Koutroumanidis M, Bruno E. Epileptology of the first tonic-clonic seizure in adults and prediction of seizure recurrenc. Epileptic Disord. 2018;20

(6)490-501. doi: 10.1684/epd.2018.1014 [Crossref]

05. Murray CJ, Lopez AD, editors. Global Comparat ive Assessment in the Health Sector; Disease Burden, Expenditures, and Intervention Packa ges. Geneva- World Health Organization. 1994. [Crossref]

06. Hesdorffer DC, Logroscino G, Benn EK, et al. Estimating risk for developing epilepsy- a population-based study in Rochester, Minnesota. Neurology. 2011 Jan4;76(1)23-7.

doi: $10.1212 /$ WNL.0b013e318204a36a [Crossref]

07. Kobau R, Zahran H, Thurman DJ, et al. Epilepsy surveillance among adults-19 States, Behavioral Risk Factor Surveillance System, 2005. MMWR Surveill Summ. 2008 Aug 8;57(6)1-20.

[Crossref]

08. Begley CE, Famulari M, Annegers JF, et al. The cost of epilepsy in the United States- an estimate from population-based clinical and survey data. Epilepsia. 2000 Mar;41(3)342-51. [Crossref]

09. Sillanpää M. Remission of seizures and predictors of intractability in long-term followup. Epilepsia. 1993 Sep-Oct;34(5)930-6.

[Crossref]

10. Radhakrishnan K. Medically intractable partial epilepsy. Neurol India. 1997;45;1-3.

[Crossref]

11. Shafer SQ, Hauser WA, Annegers JF, et al. EEG and other early predictors of epilepsy remissiona community study. Epilepsia. 1988;29(5)590600. [Crossref]

12. Mattson RH, Cramer JA, Collins JF. Prognosis for total control of complex partial and secondarily generalized tonic clonic seizures, Department of Veterans Affairs Epilepsy Cooperative Studies No 118 and No 264 Group. Neurology. 1996;47(1)

68-76. DOI: 10.1212/wnl.47.1.68 [Crossref]
13. Chawla S, Aneja S, Kashyap R, et al. Etiology and clinical predictors of intractable epilepsy. Pediatr Neurol. 2002 Sep;27(3)186-91.

[Crossref]

14. Eriksson KJ, Koivikko MJ. Prevalence, classification, and severity of epilepsy and epileptic syndromes in children. Epilepsia. $1997 ; 38(12) 1275-1282$.

[Crossref]

15. Camfield C, Camfield P, Gordon K, et al. Outcome of childhood epilepsy- a populationbased study with a simple predictive scoring system for those treated with medication. J Pediatr. 1993 Jun;122(6)861-8.

[Crossref]

16. Huttenlocher PR, Hapke RJ. A follow-up study of intractable seizures in childhood. Ann Neurol. 1990 Nov;28(5)699-705.

DOI: 10.1002/ana.410280516 [Crossref]

17. Gururaj A, Sztriha L, Hertecant J, et al. Clinical predictors of intractable childhood epilepsy. J Psychosom Res. 2006 Sep;61(3)343-7.

DOI: 10.1016/j.jpsychores.2006.07.018 [Crossref]

18. Berg AT, Levy SR, Novotny EJ, et al. Predictors of intractable epilepsy in childhood- a casecontrol study. Epilepsia. 1996 Jan;37(1)24-30. [Crossref]

19. Kwan P, Brodie MJ. Early identification of refractory epilepsy. N Engl J Med. 2000 Feb 3;342 (5)314-9.

DOI: $10.1056 /$ NEJM200002033420503 [Crossref]

20. Kwong $\mathrm{KL}$, Sung $\mathrm{WY}$, Wong $\mathrm{SN}$, et al. Early predictors of medical intractability in childhood epilepsy. Pediatr Neurol. 2003 Jul;29(1)46-52.

[Crossref]

21. Singhvi JP, Sawhney IM, Lal V, et al. Profile of intractable epilepsy in a tertiary referral center. Neurol India. 2000 Dec;48(4)351-6.

[Crossref]

22. Camfield P, Camfield C, Gordon K, Dooley J. What types of epilepsy are preceded by febrile seizures?- A population-based study of children. Dev Med Child Neurol. 1994;36(10)887-892. [Crossref] 
23. Semah F, Ryvlin P. Can we predict refractory epilepsy at the time of diagnosis?. Epileptic Disord. 2005 Sep;7(Suppl 1)S10-3.

[Crossref]

24. Annegers JF, Hauser WA, Elveback LR. Remission of seizures and relapse in patients with epilepsy. Epilepsia. 1979 Dec;20(6)729-37. [Crossref]

25. Berg AT, Levy SR, Novotny EJ, et al. Predictors of intractable epilepsy in childhood- a casecontrol study. Epilepsia. 1996 Jan;37(1)24-30. [Crossref]

26. Berg AT, Kelly MM. Defining intractabilitycomparisons among published definitions. Epilepsia. 2006 Feb;47(2)431-6. DOI: $10.1111 /$ j.1528-1167.2006.00440.x [Crossref]
27. Schmidt D. Two antiepileptic drugs for intractable epilepsy with complex partial seizures. J Neurol Neuro Surg Psychiatry. 1982;45;1119-1124.

[Crossref]

28. Reynolds EH, Shorvon SD. Monotherapy or polytherapy for epilepsy?. Epilepsia. 1981 Feb;22(1)1-10.

[Crossref]

29. Mattson RH, Cramer JA, Collins JF, et al. Comparison of carbamazepine, phenobarbital, phenytoin, and primidone in partial and secondarily generalized tonic-clonic seizures. $\mathrm{N}$ Engl J Med. 1985 Jul18;313(3)145-51.

doi: $10.1056 /$ NEJM198507183130303 [Crossref] 